\title{
Avanços desiguais e intenções indefinidas: a reforma do Estado do México e a estratégia de gerenciamento ${ }^{1}$
}

\section{Reforma do Estado mexicano: vários processos através de uma intensa história}

Desde a crise que começou em 1981, o governo do México tem feito grandes esforços para transformar as regras, instituições e atores que têm caracterizado o sistema político-econômico desde os primeiros anos pós-revolucionários.

Em 1981, o modelo econômico podia ser caracterizado como típico da América Latina: indústrias altamente protegidas, basicamente dependentes da exportação de matéria-prima, com um elevado nível de controle estatal, ditado principalmente pelo governo federal (através de diversas empresas públicas), priorizando o desenvolvimento interior, protegido da competição internacional.

No campo político, o sistema era formalmente democrático, com eleições livres, baseado na separação de poderes dentro de um estado federalista. Na verdade, o sistema era dirigido por um partido dominante, controlado pela intermediação de grupos ligados por uma série de vantagens clientelistas, fazendo do governo um direito e uma "propriedade" legítima de alguns grupos políticos.

A administração do Estado era flexível, com alto nível de burocratas firmemente ligados a poderosas estruturas políticas, e subordinados a corruptos e seus esquemas, onde um cargo governamental era visto como um prêmio, ou apoiado pelos grupos políticos dominantes. $\mathrm{Na}$ verdade, mal existia accountability no sistema e inexistia carreira no serviço público.

Professor do Centro para Pesquisa Econômica e Ensino CIDE, na Cidade do México

Tradução de Vanessa Meira da Silveira e revisão técnica de Danielly

Silva

Ramos 
Desde a chegada de um novo grupo político, que ocupou posições estratégicas na administração do presidente Miguel de la Madrid (19821988), importantes reformas do Estado foram lançadas em várias áreas, a maioria aplicada de forma abrangente, e claramente afetadas pelos eventos políticos. Entretanto, podemos dizer que a reforma econômica foi prioridade desses grupos. Transformações importantes aconteceram, começando com a idéia de que o governo não mais poderia ser o único propulsor de desenvolvimento. Privatização de empresas públicas, enxugamento da máquina administrativa e transformação econômica através da competição internacional foram tidas como metas para a implementação de uma nova estratégia, tudo isso em meio a uma severa crise econômica e política que obrigou o governo a definir novas regras para eleições e composição do Poder Legislativo.

Em termos de administração pública, a descentralização de diferentes instituições e recursos (os sistemas de educação e saúde estavam entre os mais importantes setores a serem reformados) foi definida como uma importante proposta, apesar dos esforços serem limitados pela resistência administrativa e política. Nesse contexto, a renovação do papel dos municípios foi garantida. Outra importante meta definida foi a da renovação moral da sociedade, onde a corrupção do funcionalismo público foi o alvo básico. Novos controles foram impostos aos servidores, para se ter certeza de que os recursos públicos não seriam usados de maneira imprópria por eles. Para implementar essas metas, uma nova secretaria de Estado foi criada.

Sob a administração de Carlos Salinas(1988/1994), as reformas econômicas foram consolidadas, e a transformação aprofundada. A economia começou com um processo de recuperação da crise permitindo à administração consolidar o modelo de um pequeno e ágil Estado, mas capaz de atender às demandas sociais, e apoiado por grandes níveis de capital privado nacional e internacional. Na área política, a administração negociou três diferentes reformas: do sistema, para o controle, e administração de eleições. Administrativamente, o esforço da descentralização foi mantido, mesmo encarando ainda forte oposição e outras dificuldades. Ademais, a simplificação de procedimentos e o desenvolvimento de formas mais precisas para controlar o uso de recursos públicos foram definidos. O Banco Central ganhou autonomia, e novas redes de governo foram melhoradas e redefinidas.

As diferentes iniciativas delineadas durante este período podem ser caracterizadas dentro da estratégia de reforma estatal. A reforma do Estado mexicano não deve ser explicada como um processo simples, racional e lógico. Consiste numa série de processos impostos pelos mais altos níveis do governo usando, formal e informalmente, capacidades 
discricionárias do presidente (Elizondo, 1995, p.95). Também é muito importante dizer que esses projetos ajudaram a criar um novo sistema de alianças para definir novas regras para o sistema político-econômico (Heredia, 1994, p.45), mas, freqüentemente, usando os mesmos canais clientelistas, presidencialistas e autoritários.

Como a OECD afirmou, não há modelo único ou soluções únicas para problemas governamentais (OECD, 1995, p.19). Para o caso do México, podemos dizer que a reforma do Estado, que começou em 1982, tem sido conduzida de forma gradual, de maneira firme no campo econômico, defensiva no político, e limitada no campo administrativo. ${ }^{2}$

Dadas as mudanças políticas pelas quais o país tem passado desde 1982, este aparente desequilíbrio entre as diferentes reformas lançadas no México é compreensível. Primeiro, o grupo que subiu ao poder em 1982 tem sido parte da rede institucional econômico-financeira de governo (Banco Central, Tesouro, Planejamento e Orçamento). Isto é importante porque dá a eles uma experiência comum e ideologias econômicas. Segundo, este grupo também desenvolveu uma rede de alianças com membros e instituições da comunidade financeira internacional. Todos esses elementos devem ser entendidos num contexto de severa crise fiscal, onde o déficit do governo se torna um grande problema para o desenvolvimento.

A revisão da reforma econômica evidencia que as metas dos projetos econômicos foram claras desde o início: estabilização da economia, privatização, reforma fiscal, desregulamentação econômica, reforma financeira, liberalização do comércio e renegociação da dívida externa (ASPE, 1993, p.11; REBOLLEDO, 1993, p.115-144).

Entretanto, a reforma política (basicamente reforma do sistema eleitoral) tem sido exigida por diferentes grupos de pressão. O governo e o partido dominante (PRI ou Partido Revolucionário Institucionalizado) agiram essencialmente de forma defensiva, procurando manter o controle sobre os recursos, as normas e instituições. Durante a administração de Miguel de la Madrid (1982-1988), um novo código para a regulamentação das atividades eleitorais foi implantado após a crise eleitoral de 1986, quando o candidato a governador do PAN — (Partido da Ação Nacional) ao estado Chihuahua perdeu as eleições. Muitos políticos da oposição e acadêmicos pensaram que aquelas eleições foram conduzidas através de estratégias fraudulentas pelo governo federal e pelo PRI. Sob a administração do antigo presidente Salinas(1988-1994), três reformas eleitorais foram implantadas (PRUD-HOMME, 1996, p.93), todas dirigidas por diferentes pressões políticas, e todas sofrendo forte resistência do governo e do PRI, que não queriam perder o controle sobre os recursos, normas e instituições eleitorais. Várias "reformas políticas" têm sido desenvolvidas 
desde 1978 no México. Entretanto, é sintomático que é no período em que o conflito social e a pressão ganharam força (desde as conflitantes eleições de 1988, quando Salinas chegou ao poder em meio a severas dúvidas quanto à legitimidade de sua vitória eleitoral), em que encontramos quase todos os mais importantes avanços em termos de autonomia eleitoral e transparência (MúNDEZ, 1994, p.195-196). Aparentemente, a reforma política no México não tem sido parte integral das intenções dos reformistas governamentais, assim como a reforma econômica. Talvez a reforma política tenha sido parte de uma tática defensiva, com vistas a manter o controle do sistema político e dos recursos governamentais pelo maior tempo possível.

A reforma administrativa implantada nas duas últimas administrações é, na verdade, mais difícil de entender que as reformas econômica e política. Um governo receptivo e confiável constitui um conceito que apareceu posteriormente em todos esses processos de reforma. Várias e importantes mudanças vêm ocorrendo na administração pública do México nos últimos anos (por exemplo, autonomia do Banco Central, descentralização de importantes agências federais e transformação de redes governamentais para regulamentação de diferentes atividades). Entretanto, essas mudanças não foram delineadas e implementadas através de um programa global e integral. Podemos dizer que nenhuma destas mudanças buscaram explicitamente uma transformação global do sistema da administração pública como um todo. Seguindo a suposição de que instituições governamentais são delineadas e reformadas para servir fins políticos(HAGGARD, 1996, p.4), é possível entender, dada a importância das reformas políticas e econômicas, a aparente limitação dos esforços de reforma administrativa. Dois fatores gerais podem explicar esta situação:

1) os custos, pressões, exigências geradas pelas reformas econômica e política normalmente levam os países a perceberem que o aparato administrativo governamental também precisa de reforma (HEREDIA WoONG e SCHNEIDER, 1996, p.1). Em outras palavras, a reforma mexicana está agora madura, tendo chegado a hora para uma reforma administrativa. A administração do presidente Zedillo (1994-2000), incluindo o Programa Oficial para a Modernização da Administração Pública(1996), que indica as intenções do governo (serviço público, sistemas de accountability e mudança da cultura do serviço dentro das repartições públicas, por exemplo), indica uma crescente consciência de que a hora para um segundo passo chegou;

2) porém, no caso do México, particularidades institucionais, culturais e políticas da administração pública levam a uma interpretação diferente. $\mathrm{O}$ "segundo passo", um plano integral para uma reforma administrativa global que realmente transforme o aparato estatal numa organização receptiva, 
profissional e confiável, pode prejudicar o controle político sobre os recursos, instituições e pessoas que os grupos no poder costumavam ter. Grupos políticos têm um elevado grau de controle sobre o modo como a administração pública é conduzida. O presidente ainda possui grande poder sobre os recursos públicos; pode nomear, readmitir ou demitir servidores sem nenhuma explicação; e pode freqüentemente ter acesso a recursos monetários sobre os quais ninguém mais tem controle. Ministros podem, livremente, definir sua equipe juntamente com seu secretariado. Servidores públicos são responsáveis apenas perante seus chefes administrativos ou políticos, e não possuem clara obrigação de informar ao público ou a grupos sociais informais sobre os impactos sociais e políticos dos programas governamentais. Em outras palavras, instituições da administração pública são um fator-chave para a continuação do atual "modus operandi” da política. Um sistema de serviço público reduziria drasticamente o poder do Executivo para mover, remover, gratificar, punir e manter alianças de grupos políticos que vêem o serviço público como um meio de fortalecimento político e econômico. Um sistema de accountability, em todos os níveis, reduziria drasticamente a arbitrariedade sobre as finanças públicas, que são usadas para dar a diferentes programas políticos (legítimos ou não) possibilidades de serem sustentados através de canais estatais, utilizando-se de recursos públicos. Além disso, permitiria à sociedade, imprensa, grupos políticos e ONGs obterem informação detalhada sobre o uso do dinheiro, recursos e o impacto das políticas públicas. A manutenção de forte controle sobre a informação tem permitido o uso da máquina pública como instrumento para atividade política de diferentes grupos e coalizações. Dadas estas condições, pode ser plausível dizer que uma reforma administrativa que aja sobre essas questões tem pouca probabilidade de ser implantada num curto período de tempo no México.

Entre as reformas administrativas propostas, há uma estratégia que poderia ser implantada sem muito afetar a estrutura política embutida na administração pública do México: a estratégia gerencial. Com isso, queremos dizer uma estratégia que dá ênfase à implementação de melhores técnicas para transformar burocracia em paradigma pós-burocrático (BARZELAy, 1992) (Osborne e GAEBler, 1992). Esta estratégia, baseada na reengenharia, na qualidade total e na burocracia orientada para os serviços, por exemplo, permitiria uma reforma administrativa que estabeleceria certas melhorias na eficiência e na eficácia sem transformar, substancialmente, a administração pública atual, e sem enfraquecer o tradicional sistema político de controle.

Em outras palavras, uma opção possível seria implementar um plano intermediário sem risco, uma reforma "neutra", que tecnicamente melhorasse a eficiência do governo através de técnicas administrativas. A agenda 
gerencial inclui aspectos tais como: planejamento de corporação, para especificar a atividade de cada departamento; planejamento orçamentário, assegurando que os recursos escassos sejam distribuídos eficientemente; burocracia voltada para o atendimento ao cidadão, visto como cliente e trabalho em equipe, entre os burocratas, para melhorar a eficiência e motivação (HuGHES, 1994).

É possível que o "segundo passo", a reforma administrativa que está sendo desenvolvida ainda nessa administração, não consiga implementar plenamente um sistema de administração pública e procedimentos para uma efetiva accoutability, e que, ao invés disso, venha dar ênfase à estratégia gerencial, não somente pela maior facilidade de implementação e por sua "neutralidade" política, mas também, pelo menos no início, por não pôr em risco o controle tradicional sobre a administração pública.

No apêndice, há um sumário bastante útil sobre os diferentes esforços de reforma nas áreas econômica, política, social e administrativa iniciadas no México desde as crises de 1982. O objetivo do apêndice é apenas o de apresentar um "mapa" simples e limitado das tentativas oficiais de transformar o governo mexicano, sem fazer nenhuma análise profunda de cada um ou uma avaliação de suas estruturas ou consequiências, o que será feito ao longo deste trabalho. O nosso objetivo ao apresentar este apêndice é de desenvolver uma descrição simplificada das diferentes alternativas buscadas durante todos esses anos no México.

A próxima parte deste trabalho descreve a reforma administrativa oficialmente anunciada pela presente administração, em termos de suas possibilidades e limites, de acordo com a estrutura anteriormente desenhada. Esperamos, com esta parte, justificar algumas hipóteses preliminares que encorajem pesquisas futuras.

\section{A reforma administrativa mexicana: uma reforma gerencial}

Como podemos observar, a partir da simplificada apresentação no apêndice, a reforma do Estado mexicano percorreu um longo caminho no campo econômico, avançou significativamente (apesar da defensiva posição do governo) no campo político e eleitoral, mas fez apenas poucos progressos no campo social, e menos ainda no sistema administrativo.

Há sentido em considerar que a principal explicação para isto é que a reforma política e econômica geraram uma nova dinâmica, permitindo a formação e o fortalecimento de novos grupos, desenvolvendo, pouco a pouco, diferentes estruturas de poder e transformando antigas redes de poder. Sob essas condições, o sistema administrativo, que operava sob as antigas circunstâncias políticas e econômicas, também haveria de mudar. 
O sistema administrativo precisa se adaptar a essas novas condições para se ajustar melhor à nova dinâmica gerada pelas demais reformas. Em outras palavras, a reforma administrativa vem depois das reformas econômica e política.

Entretanto, pelo menos para o sistema mexicano (e talvez para outros países também), a transformação do sistema administrativo pode ser tão difícil de se implantar quanto as outras reformas. Talvez o maior erro seja pensar no aparato governamental como um instrumento, como um conjunto de organizações, regras, instituições e pessoas especificamente designadas para obedecer às ordens. Nada poderia estar mais longe da verdade.

Pelo menos duas características são necessárias para se entender a complexidade de uma reforma administrativa: o aparato estatal é parte fundamental da estrutura de poder, e não é um harmonioso conjunto de organizações dentro de uma rede congruente (AREllano e Coronilla, 1993). Neste trabalho, enfatizamos o primeiro fator.

Primeiro, o sistema político e administrativo no México está mudando rapidamente, e algumas características aqui discutidas estão em constante transformação. Entretanto, pensamos que essas mudanças não afetam substancialmente nossa discussão e nossas conclusões. A administração pública mexicana é permeada e definida pelo corporativismo e pelo sistema presidencialista. Como os cargos eletivos são, na realidade, nomeados pelo presidente, a estrutura de accountability e informação é quase inexistente. A capacidade de vigilância e controle do Congresso ainda é frágil e pouco desenvolvida, enquanto uma nova distribuição do poder está sendo criada pelos partidos de oposição, que vêm ganhando cadeiras no Congresso nos últimos anos. Funcionários públicos desenvolvem accountability apenas com relação aos seus chefes diretos (dentro de uma rede política ou administrativa, formal ou informal). O presidente e seu gabinete podem nomear, remover ou redefinir equipes ao seu belprazer. Recursos públicos podem, quase que livremente, ser manipulados e podem ser usados, sem restrição, para suprir e apoiar escusos projetos políticos. Um sistema de informação governamental aberto, completo e acessível ao povo, é fraco, e não é claro até que ponto oficiais do governo podem ser obrigados a fornecer informações. Logo, a sociedade e outros atores políticos não possuem fácil acesso à informação sistemática e completa sobre programas públicos, despesas e avaliação de resultados. Recursos públicos são, pois, instrumentos para projetos políticos (ARELlANO e CABRERo, 1993). Uma organização pública raramente é avaliada pelos seus resultados e impactos, mas sim pela capacidade do administrador em concluir tarefas políticas específicas dentro de certo esquema político.

Em outras palavras, o sistema da administração pública, no México, é uma peça estratégica nos canais de controle político. Dado este fato, 
não é raro que uma reforma administrativa global tenha sido amplamente adiada. Desta forma, para gerar um sistema accountable, transparente e externamente controlado, seria necessário ameaçar o controle político que o grupo dominante tem-se aproveitado nas últimas décadas.

Contudo, a administração do presidente Zedillo lançou um importante projeto de reforma administrativa, talvez o mais (pelo menos formalmente) ambicioso e completo que já houve. O "Programa de Modernização da Administração Pública 1995-2000” (1996) relaciona imediatamente a reforma administrativa com a necessidade de desenvolver a reforma econômica do país: "avanços atingidos na última década pelos governos do Reino Unido, Canadá, Nova Zelândia, Austrália, e mais recentemente, Estados Unidos, Portugal e Espanha, mostram que, atualmente, mais do que nunca, atitudes governamentais causam impacto positivo ou negativo nas condições de desenvolvimento industrial e comercial, assim como nas condições de vida de seus habitantes"(op. cit. p. 1).

Este programa inaugura palavras há muito esquecidas no setor público mexicano: accountability, direitos do cidadão, direitos de informação e avaliação. Após um limitado diagnóstico, o programa propõe dois objetivos:

1) transformar a administração pública federal numa organização que age eficientemente, e com eficácia, através de uma nova cultura de serviço;

2) lutar contra a corrupção e a impunidade, através de mecanismos preventivos e promoção da capacidade dos recursos humanos.

O programa propõe quatro subprogramas diferentes: participação e atendimento ao cidadão, descentralização administrativa, avaliação e impacto da gestão pública, e profissionalização e ética para os funcionários públicos.

Seria interessante discutir, de maneira especulativa, as possibilidades reais deste programa sob duas óticas diferentes: accountability e serviço público.

Accountability: o programa acentua, em seu discurso, a questão da responsabilidade. Basicamente, na apresentação e no diagnóstico. Entretanto, os subprogramas mal se referem ao impacto das ações nesta questão. O subprograma de participação do cidadão se refere basicamente a maior acesso à informação no que concerne aos serviços públicos, redução dos procedimentos e necessidade das agências públicas de monitorar seus "clientes". Não há tentativa de grande transformação sobre a maneira pela qual o governo controla a informação em relação a impactos, custos e orçamentos designados a programas ou serviços. Não há um programa de ação onde os "clientes" controlariam o processo e os resultados da avaliação dos órgãos públicos. O subprograma de descentralização dá ênfase na melhoria de condições para prover os serviços públicos, e 
na flexibilidade das instituições públicas deveriam ter para responder às novas necessidades eficientemente. A idéia é que uma maior accountability seria naturalmente produzida através de uma melhor distribuição técnica de recursos e responsabilidade. Accountability é considerado um assunto interno, onde a eficiência tem maior importância que um amplo e aberto sistema de informação ao público. O subprograma de avaliação e de impacto da atividade pública gerencial anuncia o desenvolvimento de um sistema integrado de informação, além de novos indicadores de performance. No entanto, o subprograma propõe estes sistemas para controle interno. Melhor informação para melhorar o gerenciamento interno, objetivos claros e resultados mensuráveis para avaliação interna, indicadores de desempenho para orientar o processo decisório do gerenciamento. Não há proposta sobre formas de controle da atividade pública através dos cidadãos ou do Congresso por exemplo. Não há referência sobre avaliação externa dos impactos sociais dos programas públicos. O ponto mais importante é o que se refere ao processo de tomada de decisão na gestão interna.

Serviço Público: o subprograma de profissionalização e ética do serviço público traz uma oportunidade há muito esperada no México: a implantação de um serviço público de carreira. Entretanto, o programa ainda é muito geral, induzindo cada órgão a definir seus próprios procedimentos para contratação e desenvolvimento dos recursos humanos. O programa explica que, em 1997, o governo deverá definir as características específicas da carreira no serviço público. Será muito importante, nesse momento, analisar as possibilidades reais da proposta.

Nossa explicação preliminar e especulativa para esta aparente falta de critérios para uma reforma que pode transformar a administração pública em um aparato accountable e controlado externamente é simples: uma tal transformação enfraqueceria o controle político. A obrigação de prestar informação ao público, não somente a respeito de procedimentos nos serviços públicos, mas também em termos de orçamentos, impactos, avaliações, resultados e fluxo de recursos dentro das agências e departamentos, reduziria a arbitrariedade de certos servidores de primeiro escalão ao sustentar agendas políticas particulares através de suas instituições. Além disso, a informação sobre os resultados dos programas oficiais e seu impacto sobre determinados grupos sociais seria acessível aos outros grupos políticos. Porém, reduziria a flexibilidade de destinação de recursos e de manipulação (por meio de punição ou recompensa) de grupos sociais e/ou políticos. O desenvolvimento de regulações específicas e de canais institucionais, que permitiriam conectar a sociedade e o Congresso aos mecanismos básicos de avaliação de desempenho dos órgãos públicos, imporia severas limitações ao alto escalão em relação ao desenho e implementação de políticas públicas. O processo de tomada de decisão 
na área das políticas públicas, hoje desenvolvido basicamente em gabinetes de ministérios, seria afetado pela "introdução" de novos grupos e atores, se um sistema aberto de informação fosse implantado.

Por último, a implementação de um sistema de funcionalismo público legítimo reduziria a quase total arbitrariedade nos órgãos estatais sobre os recursos humanos e materiais que o alto escalão desfruta. Este sistema implicaria cultura e valores diferentes, onde funcionários nomeados teriam de negociar com as burocracias, limitando a capacidade de manipulação dos recursos para determinadas agendas políticas (legítimas ou não). Mais ainda, dada a cultura política atual no México, uma reforma no funcionalismo poderia tornar "refém" da rede política de clientelismo e corporativismo ainda existente e repleta de quadros burocráticos inflexíveis e fechados.

A atual reforma administrativa, até o presente momento, tem claramente procurado alternativas intermediárias. Parece que a melhor solução, segundo os reformadores do governo, seria achar uma maneira de aumentar a eficiência e transformar o aparato público de forma atender à demanda social, sem prejudicar o controle político atual, que tradicionalmente depende da manipulação de órgãos governamentais e do poder sobre a informação (algumas análises preliminares parecem concordar com esta interpretação da reforma em curso, como Múndez, 1996, p.26-27).

Pela linguagem usada no programa, e algumas experiências já desenvolvidas nesta administração, parece que os reformadores do governo, assim como em muitos outros países, acharam uma alternativa que pode ser chamada de gerencialismo (LynN, 1996). Em poucas palavras, gerencialismo constitui uma forma de crença, encontrada em diversas partes do mundo, nas técnicas gerenciais privadas para resolver o problema da burocratização governamental. Documentos famosos proclamam (como os de Osborne-Gaebler e Barzelay) o fim da Era burocrática e o início da Era do paradigma pós-burocrático.

Este não é o lugar para se ir mais a fundo na crítica e análise do gerencialismo. Isto foi feito em estudos anteriores (ArELlano, 1995). Porém, é possível dizer que para reformadores mexicanos o gerencialismo atende não somente às questões de eficiência e eficácia, mas também promove reformas administrativas menos "dolorosas". Isto porque o gerencialismo, voltando à antiga dicotomia política-administração, lida com questões mais administrativas que políticas, através de altas doses de técnicas "neutras" de gerenciamento aplicadas a situações do setor público.

As técnicas gerenciais são técnicas relativamente fáceis de se implementar pelo menos nas fases iniciais, não requerem grandes transformações em questões como accountability e reformas do serviço público. Em outras palavras, assume-se que é possível chegar a um governo eficiente sem mudar a atual natureza do Estado e suas políticas. 
Através deste trabalho, afirmamos que a transformação da administração é também a transformação da política. Pensamos realmente que existem severas limitações políticas para a implantação de uma profunda transformação ou reforma na administração pública mexicana. Como elemento fundamental de controle político, os órgãos públicos e seus reformadores também resistiriam em fornecer informação e mecanismos de controle de recursos para a sociedade ou o Congresso. Isto será, com certeza, um longo processo de controvérsia social. Para que se fale em reforma administrativa mexicana, uma série de etapas terá de ser percorrida, assim como tem acontecido nas esferas econômica e política. O primeiro dentre os mais importantes passos - usar a estratégia gerencial, evitando o problema-chave de tornar o governo accountable - foi lançado pelo governo mexicano dentro do atual programa de modernização.

Parece importante analisar os erros e acertos das estratégias gerenciais, mantendo-se a tese de que a transformação administrativa também constitui uma transformação política. O estudo profundo das possibilidades de implantação de um sistema de carreira para o funcionalismo público, agora que será lançado um programa específico, parece ser substancial para se entender o futuro da reforma do Estado mexicano. 
1 Este paper foi preparado para a primeira reunião do projeto "Democratização, liberalização econômica e reforma do Estado: Coréia na perspectiva comparativa", realizada de 30 a 31 de maio de 1997 pelo Center for International and Comparative Studies da Morthwesterin University, com o objetivo de apresentar um conjunto de idéias e proposições básicas quanto ao México, que auxiliariam ao aprimorar e focalizar a pesquisa da agenda para este projeto.

2 Outras reformas administrativas foram feitas no México antes de 1982. Para maior aprofundamento ver Pardo (1991). 


\section{Referências bibliográficas}

Aguiar Villanueva, Luis. "La silenciosa, heterodoxa reforma de la administración pública mexicana”, in Revista de Administración Pública, Mexico, INAP, n. 91, p. 19-26, 1996.

Arellano, David. "Gestión pública en Estados Unidos: crisis y estado del arte". In: Gestión y Política Pública. Vol. IV. n. 1. Mexico. CIDE, 1995.

and Raúl Coronilla. "Cambio y organizaciones públicas: fuentes y perspectivas de análisis desde la teoría de la organización”. Documentos de Trabajo. Num. 20. Mexico. CIDE, 1993.

and Enrique Cabrero. "Modelos organizacionales autóctonos para

América Latina. ¿Utopía o realidad?”. Documentos de Trabajo. Mexico. CIDE, 1993. AsPE, Pedro. El camino mexicano de la transformación económica. Mexico. FCE, 1993.

BARZELAY, Michael. Breaking through bureacuracy. Berkeley. University of California Press, 1992.

Elizondo, Carlos. "El Estado mexicano después de su reforma" in Política y Gobierno. vol. II. n. 1. 1st semester. Mexico. CIDE, 1995.

HaGgard, Stephen. The reform of the state in Latin America. Draft, 1995.

Haro Belchez, Guillermo. Aportaciones para la Reforma de la Función Pública en México. Madrid, Instituto de Administración Pública, 1988.

Heredia, Blanca. "Estructura política y reforma económica: el caso de México" in Política y Gobierno. Vol. I. n.1. 1st semester. Mexico. CIDE, 1994.

Kwang Woong and Ben R. SchNeIDER. 1996. Democratization, economic liberalization, and reforming the state: Korea in comparative perspective. Project Proposal, 1996.

Hughes, Owen. Public management and administration: an introduction. New York. St. Martins Press, 1994.

Instituto Federal Electoral. Código Federal de Instituciones y Procedimientos Electorales. Mexico. IFE, 1996.

KAUFMAN, Robert. The politics of state reform: a review of theoretical approaches. Draft, 1997.

KLIKSBERG, Bernardo. El rediseño del Estado. Una perspectiva internacional. Mexico. F.C.E., 1994.

LYNN, Laurance. "Reforma administrativa desde una perspectiva internacional: ley pública y la nueva administración pública". in Gestión y Política Pública. V. 5 n. 2. Mexico. CIDE, 1996.

MenDEZ, José Luis. "Reforma del Estado, democracia participativa y modelos de decisión" in Política y Cultura. Auttum. N. 7. Mexico. UAM-X, 1996.

. "La reforma del Estado en México: alcances y límites". in Gestión y Política Pública. Mexico. CIDE, 1994.

Merino, Mauricio. "De la lealtad individual a la responsabilidad pública”. In: Revista de Administración Pública, Mexico, INAP, n. 91. p. 5-18, 1996.

Osborne, David and Ted, Gaebler. Reinventing government. New York. Addison Wesley, 1992.

Organization For The Economic Cooperation And Development (OECD). Governance in transition: public management reform in OECD countries. Paris. OECD, 1995.

PARdo, María del Carmen. La modernización administrativa en México. Mexico. COLMEX, 1991. 
Programa de Modernización de la Administración Pública. 1995-2000. Mexico. Poder Ejecutivo Nacional, 1996.

Prud-Homme, Jean-Francois. "La negociación de las reglas del juego: tres reformas electorales (1988-1994)" In Política y Gobierno. v. III. n.1, 1996.

Rebolledo, Juan. La reforma del Estado en México. Mexico. Fondo de Cultura Económica, 1994. 


\section{Avanços desiguais e intenções indefinidas: A reforma do Estado do México e a estratégia de gerenciamento.}

David Arellano Gault

Este paper defende duas idéias. A primeira, é apresentar os diferentes processos da reforma do Estado mexicano, analisados sob as prioridades diversas no decorrer do tempo. As reformas econômica, política, social e administrativa tiveram prioridades e objetivos divergentes. A reforma econômica foi sistemática e congruente, a política foi defensiva e pouco abrangente, e a social foi problemática e confusa. A reforma administrativa foi, comparativamente, limitada. Uma proposta para desenvolver um sistema administrativo responsável pelo serviço público foi postergada nos últimos 12 anos até que, em maio de 1997, finalmente a atual administração propôs um programa de modernização.

A segunda idéia é que, mesmo que a atual administração tenha a intenção de desenvolver um novo sistema de accountability e um plano de carreira para o serviço público, parece plausível que a tradicional política de controle, através da estrutura administrativa, possa ser prejudicada se essas propostas realmente reduzirem o poder discricionário dos altos cargos públicos e submeterem reservas públicas a um esquema de controle social mais aberto e formal. Logo, é possível dizer que a alternativa escolhida pelos reformistas foi usar uma abordagem gerenciadora, onde a melhoria dos procedimentos e a implementação de algumas técnicas administrativas avançadas substituem, pelo menos até agora, uma transformação mais profunda da estrutura administrativa. Uma estratégia de gerenciamento permite, pelo menos até o momento, a melhoria dos serviços através do aumento da participação de servidores públicos, sem prejudicar a atual administração, como um instrumento para implementar diferentes agendas políticas usando recursos públicos. Nosso argumento é que, como o programa de modernização está sendo implantado, é importante estudar minuciosamente as possibilidades de se implementar a reforma do serviço público e melhorar a responsabilidade do sistema, dada a particular relação que existe entre a administração pública e o sistema político no México.

\section{Avances desiguales e intenciones indefinidas: la reforma del Estado en México y la estrategia de gestión.}

\section{David Arellano Gault}

Este trabajo defiende dos ideas. La primera es presentar los diferentes procesos de la reforma del Estado Mexicano, analizados bajo las prioridades diversas en el transcurso del tiempo. Las reformas económica, política, social y administrativa tuvieron prioridades y objetivos divergentes. La reforma económica fue sistemática y congruente, la política fue defensiva y de poca amplitud, y la social fue problemática y confusa. La reforma administrativa fue, comparativamente, limitada. Una propuesta para desarrollar un sistema administrativo responsable del servicio público fue pospuesta en los últimos 12 años hasta que finalmente, en mayo de 1997, la actual administración propuso un programa de modernización.

La segunda idea es que, aunque la actual administración tenga la intención de desarrollar un nuevo sistema de accountability y un plan de carrera para el servicio público, parece plausible que la tradicional política de control, por medio de la estructura administrativa, pueda verse perjudicada si dichas propuestas realmente llegan a reducir el poder discrecional de los altos cargos públicos y someter las reservas públicas a un esquema de control social más abierto y formal. Por lo tanto, se puede decir que la alternativa escogida
Ano 48

Número 3 Set-Dez 1997

Professor do Centro para Pesquisa Econômica e Ensino CIDE, na Cidade do México

Tradução de Vanessa Meira da Silveira e revisão técnica de Danielly Silva Ramos 
por los reformistas fue la de usar un enfoque de gerencia, donde la mejora de los procedimientos y puesta en práctica de algunas técnicas administrativas avanzadas han substituido, por lo menos hasta la fecha, una transformación más profunda de la estructura administrativa. Una estrategia de gerencia ha permitido, por lo menos hasta ahora, la mejora de los servicios mediante el aumento de la participación de servidores públicos, sin perjudicar la actual administración, como un instrumento para poner en práctica diferentes agendas políticas usando recursos públicos.

Nuestro argumento es que, como el programa de modernización está siendo implantado, es importante estudiar minuciosamente la posibilidad de poner en marcha la reforma del servicio público y mejorar la responsabilidad del sistema, considerando la particular relación que existe entre la administración pública y el sistema político en México.

\section{Unequal advances and unclear intentions: the mexican State reform and the managerialist strategy \\ David Arellano Gault}

The paper advocates two ideas. The first one is that the reform of the Mexican state should be analyzed as a set of different processes, with different priorities over time. Economical, political, social, and administrative reforms have had divergent priorities and intentions. The economic reform has been systematic and congruent, but the political one has been defensive and incremental, and the social reform has been problematic and confusing. Administrative reforms have been comparatively limited. A proposition to develop an accountable administrative system with a professional civil service had been postponed for the last 12 years, although this may finally change with the modernization program proposed recently by the present administration.

The second idea is that, even though the current administration has expressed its intention to develop a new system of accountability and a career system for the civil service, it seems plausible that traditional political control through the administrative structure might be jeopardized if these proposals successfully reduce the discretionary power of high public officials and subject public resources to more open and formal schemes of social control. In this sense, it is possible to say that the alternative chosen by reformers has been to use a managerialist approach, where the improvement of administrative procedures and the implementation of some advanced administrative techniques substitute, at least for the moment, a deeper transformation of the administrative structure. A managerialist strategy allows, at least on discourse, services to improve by increasing the participation of public officials, without jeopardizing the current manipulation of public administration as an instrument to implement different political agendas using public resources. It is our argument that, because this modernization program is still being developed it is important to study in greater detail the possibilities of implementing the civil service reform and improving the accountability of the system, given the particular relation that exists between public administration and the political system in Mexico. 

Administração Pública — ENAP, voltada para a divulgação e debate de temas relacionados ao Estado, à Administração Pública e à gestão governamental. Procurando o aprimoramento permanente da revista, tanto no seu conteúdo quanto na apresentação gráfica, pedimos aos nossos colaboradores a observação das normas abaixo descritas.

\section{Normas para os colaboradores}

1. Os artigos, sempre inéditos no Brasil, devem conter em torno de 25 laudas de 20 linhas de 70 toques.

2. Os originais devem ser encaminhados ao editor, em disquete, em programa de uso universal, com uma cópia impressa. Usar apenas as formatações-padrão.

3. Cada artigo deve vir acompanhado de um resumo analítico em português, espanhol e inglês, de cerca de 150 palavras, que permita uma visão global e antecipada do assunto tratado.

4. Na primeira página do artigo, deve constar informação sobre formação e vinculação institucional do autor (em até duas linhas).

5. Notas, referências e bibliografia devem vir ao final do artigo, e não ao pé da página. Notas e referências, sendo o caso, devem vir devidamente numeradas.

6. Além de artigos, a revista receberá comunicações, notas informativas, notícias e relatórios conclusivos de pesquisas em desenvolvimento, com até 15 laudas. Resenhas de livros, em torno de 4 laudas, devem conter uma apresentação sucinta da obra e eventuais comentários que situem o leitor na discussão.

7. Os trabalhos que se adequarem à linha temática da revista serão apreciados pelo conselho editorial, que decidirá sobre a publicação com base em pareceres de consultores ad hoc.

8. Os originais enviados à Revista do Serviço Público não serão devolvidos. A revista comprometese a informar os autores sobre a publicação ou não de seus trabalhos.

\section{Convite a resenhadores}

A Revista do Serviço Público convida todos os interessados em remeter resenhas de trabalhos publicados no Brasil e no exterior sobre Estado, Administração Pública e gestão governamental.

As resenhas devem ser originais e não exceder a cinco laudas datilografadas em espaço duplo com 20 linhas de 70 toques, e devem apresentar de modo sucinto a obra, com comentários que situem o leitor na discussão apresentada.

As resenhas devem ser enviadas em português, sem notas de rodapé, contendo o título completo e subtítulo do livro, nome completo do autor, local de publicação, editora e ano de publicação, bem como uma breve informação sobre a formação e vinculação institucional do resenhador (em até duas linhas), acompanhadas do respectivo disquete.

\section{Nota aos editores}

Pedimos encaminhar à Revista do Serviço Público exemplares de livros publicados, a fim de serem resenhados. Os resenhadores interessados receberão cópias dos livros enviados. 